\title{
CORRECTION
}

View Article Online

View Journal | View Issue

Check for updates

Cite this: J. Mater. Chem. A, 2020, 8 13853

DOI: 10.1039/d0ta90132f

rsc.li/materials-a

\section{Correction: A new strategy for the controllable growth of MOF@PBA architectures}

Xiao Xiao, ${ }^{a}$ Guangxun Zhang, ${ }^{a}$ Yuxia Xu, ${ }^{a}$ Hualin Zhang, ${ }^{a}$ Xiaotian Guo, ${ }^{a}$ Yong Liu $^{b}$ and Huan Pang*a

Correction for 'A new strategy for the controllable growth of MOF@PBA architectures' by Xiao Xiao et al., J. Mater. Chem. A, 2019, 7, 17266-17271, DOI: 10.1039/C9TA05409J.

The authors want to clarify the correct details of Fig. 3 in the published article. There was an error in the vertical axis label of Fig. 3e in the published article. The vertical axis label should be "Current density ${ }^{-1}\left(\mathrm{~mA}^{-1} \mathrm{~cm}^{2}\right)$ ". A corrected version of Fig. 3 is provided here:
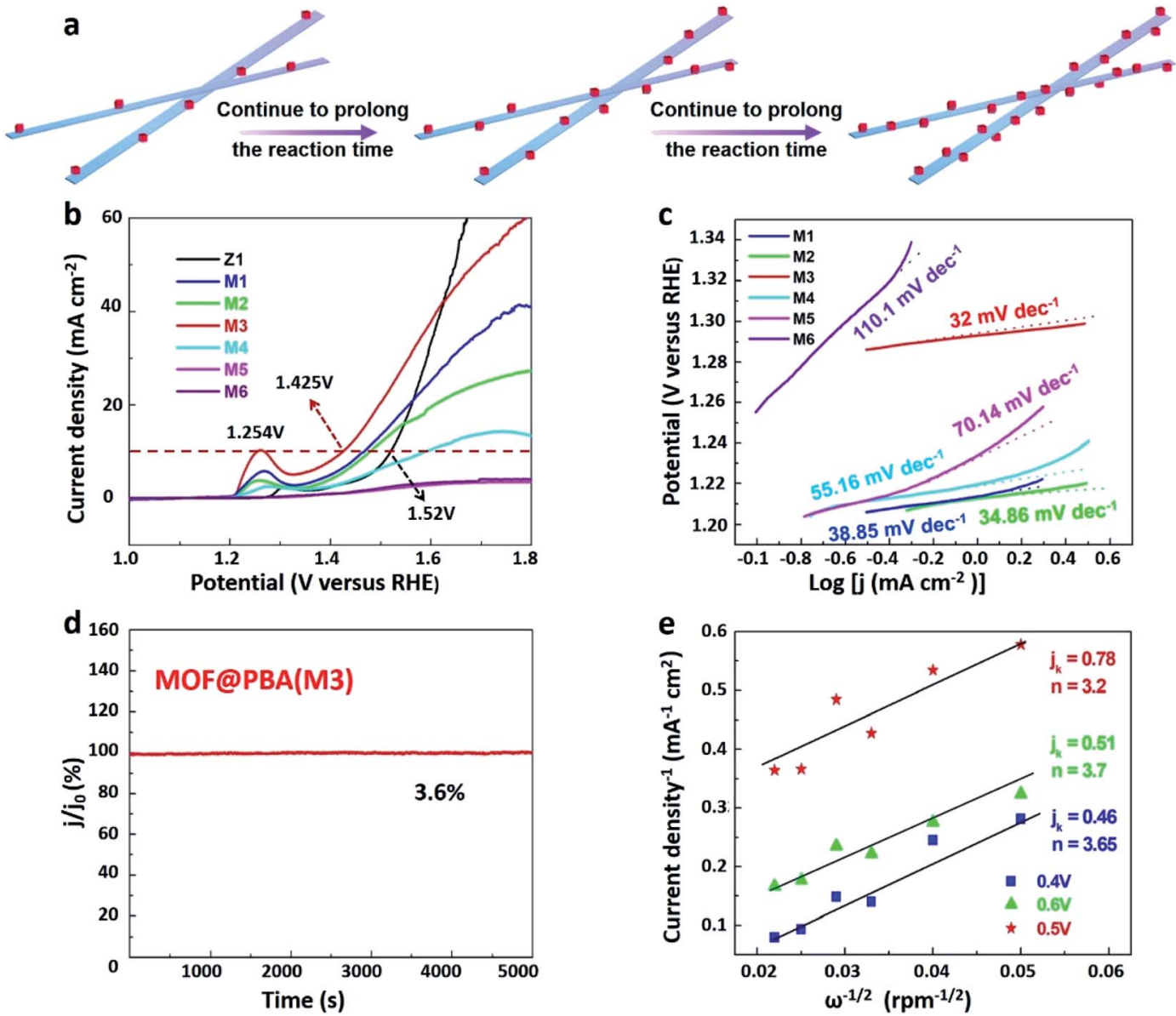

Fig. 3 Schematic diagram (a) of the effect of prolonging reaction time on the morphology. Comparison of (b) OER performance in $1.0 \mathrm{M}$ KOH and (c) corresponding Tafel slopes; (d) chronopotentiometry curves; (e) Koutecky-Levich plots at $0.4 \mathrm{~V}, 0.5 \mathrm{~V}$ and $0.6 \mathrm{~V}$. 
Furthermore, the authors want to clarify the correct details of three figures in the Electronic Supplementary Information of the published article.

In the originally published version of our Electronic Supplementary Information, the details of Fig. S13 were incorrect. When processing the XRD data, we misarranged the order of M10 and M11, resulting in errors. A corrected version of Fig. S13 is provided here:

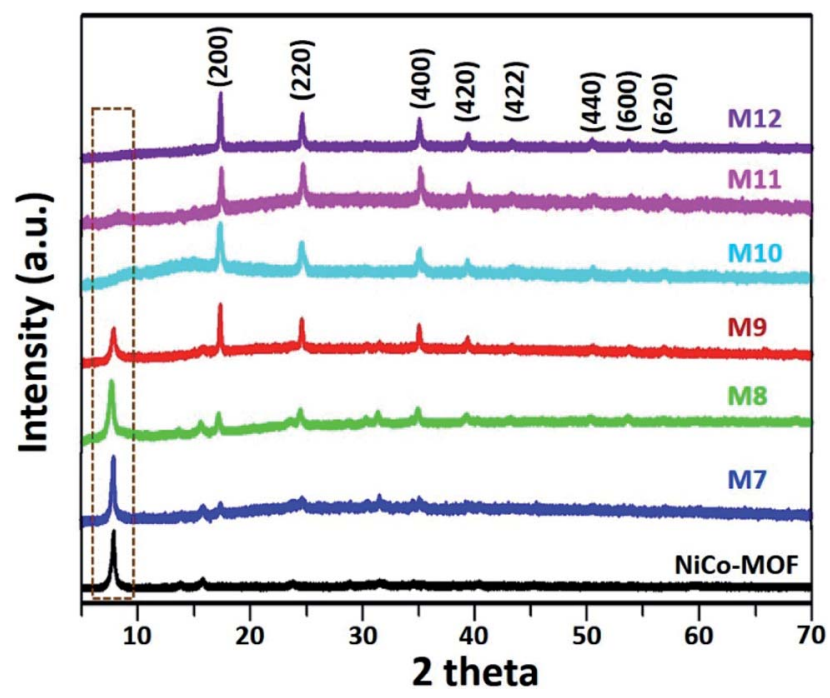

Fig. S13. XRD patterns of the NiCo-MOF@PBA.

In addition, the vertical axis label of Fig. S20 should be "Potential (V versus RHE)". A corrected version of Fig. S20 is provided here:

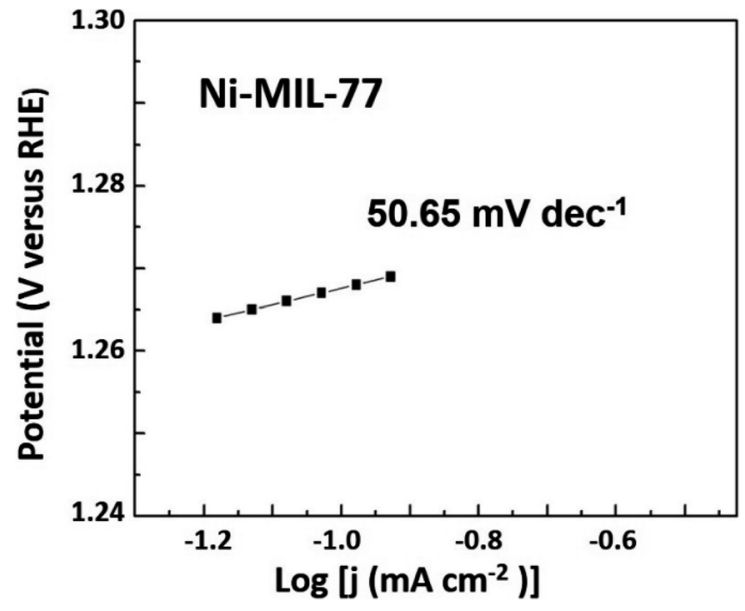

Fig. S20. Polarization curve derived Tafel plots of the Ni-MIL-77. 
Finally, the vertical axis label of Fig. S24 should be "Current density ${ }^{-1}\left(\mathrm{~mA}^{-1} \mathrm{~cm}^{2}\right)$ ". A corrected version of Fig. S24 is provided here:

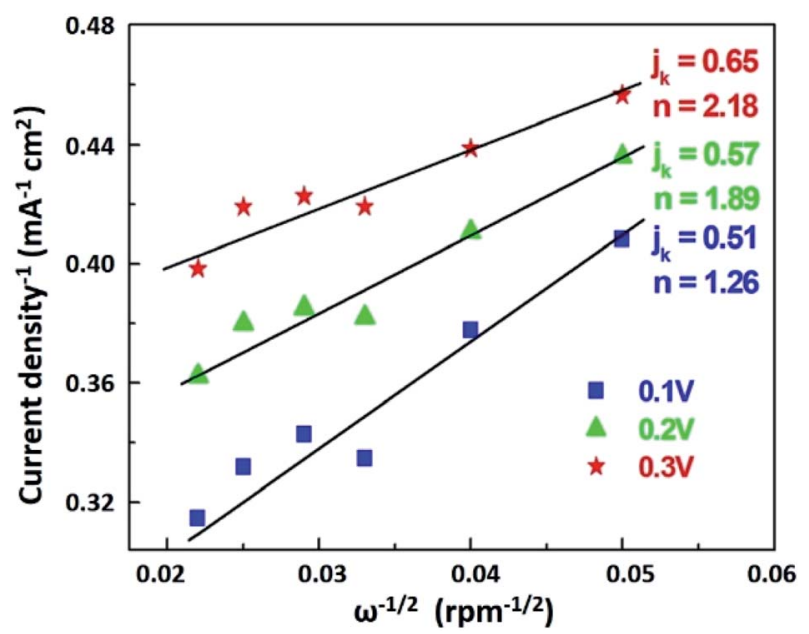

Fig. S24. Polarization curve derived Tafel plots of the Ni-MIL-77.

These corrections will not affect the experimental conclusions.

The Royal Society of Chemistry apologises for these errors and any consequent inconvenience to authors and readers. 